\title{
Organizational Sustainability: The Case of Handcrafts Micro-Business in Southern San Sebastian, Jalisco, México
}

\author{
José G. Vargas-Hernández \\ National System of Researchers of Mexico, \\ University Centre for Economic and Managerial Sciences, University of Guadalajara, \\ Núcleo Universitario Los Belenes CUCEA, Zapopan, Jalisco, \\ México
}

\section{Introduction}

The new conditions of globalization underlie life conditions and the importance of a generational future as a component of competitiveness. What constitutes globalization is the interaction that changes the scenarios for the individuals, organizations and society, who are constantly hounded by contradictory forces and uncertainties. The appropriate use of natural resources can meet present and future interests, having a change in current practices. In comparison to the economic rationality's logic that drives the functioning of organizations and has as a lead obtaining maximum present return, before that if natural resources yield greater benefit under their exploitation than taking care of them, they are sacrificed. Thus, the immediate economic profit is the current enemy of the environment. The ecological proposal in organizations, widen its model of interactions which can integrate the environmental paradigm to the organizational system. An approaching to sustainability of organizations is affected by the combination of ambiguous environmental economic policies, the abrupt adoption of production technologies and market practices. Sustainability in business organizations as an implementation strategy of process reengineering and the adoption of production technologies are oriented toward avoiding waste materials, recycling trash and eliminating toxics.

Lacking acceptance of the role that business organizations play in sustainability, it influences the global debate questioning real causes of pollution which poses safeguards to organizations and justify poverty as the main cause generating environmental degradation. It also suggests as a consequence of deterioration the inadequate economic policies that allow for business actions less friendly with the environment. This paper sets as aims, firstly to determine the level of organizational sustainability for the environmental and economic development of cutting treatment and exploitation activities of the grass called tule thypa spp from Zapotlán Lake. Similarly, the paper pretends to analyze potentialities and economic benefits derived from a marketing orientation of international business in the making of art craft out of tule and palmilla (a kind of palm) that growth spontaneously in Zapotlán Lake. To achieve these objectives, it is drawn a conceptual, theoretical, methodological and 
contextual reference framework, out of which departs to analyze the case of art craft micro enterprises processing tule in the locality of Southern San Sebastian following the design of a traditional research beginning with the hypothesis formulation. Finally, the results are analyzed and recommendations are formulated.

\section{Organizational sustainability and organizational social capital}

A sustainable organization integrates the ecological vision and the institutional theories in organizational systemic values. The acquisition of a common sense in the production of goods and services is utilized as a stronghold to promote the eco-efficiency as a friendly culture of organizations with their environments to achieve emission reductions and rational exploitation of natural resources. The environmental variable in organizational culture is inserted as a rational interpretation of the functioning for the environmental protection, reducing insecurity and context's social pressure. Environmental protection is a technical variable composed by other environmental values such as the promotion of environmental caring, environmental risk control, adequate relationship between organizations, and integration of working groups, orientation and permanent staffing on sustainability. In addition, economic instruments tie sustainable development to micro and small business enterprises. Instruments such as governmental policies, low market tariffs to diminish costs, promotion and incentive of employment opportunities, detection of opportunity areas, etc. are required. Also, it is convenient to have the diagnostic of adaptable enterprises to sustainability because not all of the micro and small business enterprises are capable to form an environmental internal culture. From the point of view of general theory of organizations, according to studies on social capital by Baker (2000) and Burt (1997) (cited by Portes, 1999:247) it is necessary to gain a greater insight, comprehension and understanding of market competitiveness mechanisms. Similarly, Joyce (1998) focuses his analysis of social capital in the leadership phenomena. Either the organization or each one of its members can be incorporated as public and private issues to social capital. Thus, from social capital emerge two patterns, the emphasis on public goods and the emphasis on private goods.

Leana y Van Buren III (1999) define organizational social capital as a resource which reflects the character of social relations within the organization, achieved through the levels of members' orientation by collective objectives and shared trust. Social capital is a collective attribute more than aggregation of individual social connections. It is a byproduct of other organizational activities and thus, it constitutes and indispensable component for collective action. Social organizational capital is an asset whose joint possession between members and the organization benefits both. A new organization has the advantage to create its own organizational social capital in such a way that can maintain optimum equilibrium between stakeholders, individual and other organizational interests in spite of their contingent nature. This is to say, different situations and persons in their relation to organizational performance. A community accounts on social organizational capital when their organizations are characterized by relationships of trust that develop and make predictable their behavior. The capacity of a community is reflected in its level of endogenous development.

The organizations are concrete reality with resources' rules and ordinances for the pursuit of objectives. Members of an organization have as expectations to solve problems of collective action to get supply of some goods and services. Organizations that follow general strategies 
and the ones that follow strategies of niches occupy different environmental resources to produce innovative responses that form inter-dependent connections with other specialized organizations in other industries such as structures of community support. Processes of economic structural change in a local economy require profound changes in trust levels and inter-relationships of cooperation fomented by arrangements of institutions and organizations. Thus, local government must define action lines which function as a catalytic converter of the community efforts.

Finally, population ecologists suggest that the environment selects the organizations which structural features provide the highest values for adjustment, emphasizing the competitive process as a driver of institutional change. Besides, population ecology suggests that organizations founded in a specific organizational form, combined with differences on the surviving rates between organizations with different organizational forms, produce institutional change.

\section{The case of micro and small business enterprises involved in the exploitation of Tule Typha spp. from the lake Zapotlán}

\subsection{Background of the problem}

Similarly to the great majority of aquatic bodies localized in closed basins of Mexican national territory, Zapotlán Lake is the natural receptacle, dump and outlet where converge the sewage, trash and black waters from the human settlements of Cd. Guzmán and san Sebastián del Sur (Southern San Sebastián)

The presence of these natural elements form a nutrients blend that facilitates the growth and development of an abundant aquatic mix which has covered almost the totality of the mirror's surface of the lake and it extends further beyond the shores while penetrating humidity. The transformations of the environment's lake of Zapotlán have a strong impact on the population's socio-economic issues, mainly in San Sebastián del Sur in the municipality of Gomez Farías, and to a lesser extent to the settlers of Cd. Guzmán in the municipality of Zapotlán el Grande, despite the higher levels of pollution in which in is actually found

Deterioration of this lake-body has achieved alarming levels as a consequence of the increasing population and its corresponding enlarging urbanization processes, industrial, farming and agricultural activities. Specifically, one of the natural resources offered by the lake of Zapotlán, the aquatic tule typha spp has been benefiting the settlers and inhabitants of San Sebastián del Sur mainly for its exploitation through the crafting of several products and handicrafts. Thus, the exploitation of tule and the elaboration of handicrafts create direct employments and constitute the income base for around 300 families and their members, a roughly estimation of one thousand and five hundred individuals making a living out of these activities in the municipality of Gomez Farías. However, more are the benefits obtained from tule chubby and plump those other kinds, followed by the one known as palmilla (palm). In its natural habitat, the palmilla tule harms tule chubby's growing and development. This problem, among others, added to the problems derived from environmental degradation which transforms nature of Zapotlán's lake, limit the economic activities derived from the extraction of tule, whose tendency, if it is going to continue in the 
future, and threatens the disappearance of an important employment's source for living sustainability of the inhabitants in San Sebastian del Sur. To aggravate this problem, The Pan-American Olympic Games has chosen Zapotlán's Lake as the location where the aquatic games will take place the year 2011. For that reason, the lake is having a profound transformation which implies the clearance and cleaning of the lake's mirror from any type of grass and bush, including the cutting off and taking out of tule. Other factors contributing to limit the environmental and economic sustainability of development and the scope of benefits from economic activities and exploitation of tule are the following:

a. Null orientation toward a sustainable exploitation of tule as a natural resource.

b. Lack of organization between the cutters of tule and the handcrafters'

c. Weak infrastructure for the development of a more advanced handcrafted production.

d. Excessive interest of hoarders and middlemen in the processes of commercialization and distribution of elaborated products.

e. Lack of mechanisms of governmental institutions to foster and develop economic activities, such as credits, training and technical assistance.

f. Null knowledge of techniques and systems to export their products to the international markets where more acceptances have.

Until now, handcrafted products derived from tule as the main raw material, are elaborated with a strong artistic content to attend local, regional, national and international markets, which traditionally consume because there is a strong historic presence in Mexican culture since pre-colonial times. In order to be organized to attend the regional market, a group of 42 craftsmen acting as partners integrating the Association of Craftsmen (Asociación de Artesanos) initiated the construction of the "House of Craftsmen" in the early nineties to operate as an outlet for selling their products. This business still operates until now having only six partners, although it can be inferred from simple observation that the partners are undergoing heavy conflicts, dividing the building and infrastructure in small areas to operate their own personal business.

Most of the craftsmen deliver their production to middlemen who always perform as hoarders, being a link in the distribution channel and contributing to the commercialization of the handcrafted products in the local, regional and national markets and incipiently in the international markets. These middlemen are the ones who hold the greater percentage of profits. Similarly, by the same token, production is oriented to meet the fundamental needs and wishes of our own local, regional and national markets. Because it is a captive and non competitive market, craftsmen do not perform product design and product development activities. The crafted products implicitly have a higher craftsmanship content in order to meet a more sophisticated demand of international markets which value and appreciate the artistic sensibility and good taste of skillful craftsmen. These craftsmen work tule as a raw material for the creation of handcrafts. The exploitation of tule from Zapotlán's lake has followed irrational patterns which affect not only the environmental sustainability and equilibrium, but also generate problems of low family income and in the running time lesser employment for manpower. The rehabilitation of the Lake requires a more rational exploitation of tule, in such a way that does not affect the environmental sustainability and the economic activity derived and the treatment of tule, while on the other hand, also it is required to improve the family income who work tule and inclusive to generate new employments. 


\subsection{Delimitation of the problem}

Zapotlán's Lake has been consciously subjugated to environmental degradation by the inhabitants of the municipalities of Zapotlán el Grande y Gómez Farías. This situation together with the over exploitation of tule are the two are the two main factors contributing to limit sustainability of the economic activity and derived benefits of cultivation, treatment and elaboration of tule handcrafts. There are other factors that limit the sustainable development. Thus, employment creation and increasing the income of around three hundred families highly depending of the economic activity are found seriously threatened given the current conditions of development. In the last few years, the selling of tule crafted goods has been favored. However, the industry still faces certain problems, among which we can mention:

- Increments in the cost of raw materials (Wood and tule)

- Considerable increasing of craftsmen in the region

- Bad reduction of handcrafted products

- Low and slow commercialization of handcrafted products

- Little support for the promotion of their goods.

This paper is the result of a research that initiated with the following questions: What is the sustainability of the economic efficiency and environmental development of the activities and expected benefits of tule's cultivation and exploitation in Zapotlán's Lake for almost three hundred families, whose income is depending on these activities, given the dysfunctional environmental conditions in which they are actually found? What are the potentials and economic benefits derived from introducing in the international markets the handcrafted products made based on tule from Zapotlán's Lake as the main raw material?

\subsection{Objectives}

- To determine the level of organizational sustainability taking into account the economic and environmental development out of tule's cutting, treatment and exploitation activities at Zapotlan's Lake.

- To analyze potentialities and economic benefits derived from a marketing orientation of international business in the making of handcrafted products made of tule and palmilla from Zapotlán’s Lake.

\subsection{Hypothesis}

One orientation of organizational sustainability in the craft making of handcraft goods made of tule from Zapotlan's Lake as the main raw material contribute to increase family income, the economic benefits of workers and the employment creation

\subsection{Handcrafts in San Sebastian Del Sur}

In the last decades, at San Sebastian del Sur located in the municipality of Gómez Farías, the main sources of income have been agriculture, livestock, fishery and handcrafts production. The handcrafts are made from different materials that are taken from natural resources abundant in the region Southern Jalisco. Inhabitants from San Sebastian del Sur take advantage of the benefits provided by what it is known as Zapotlán's Lake that offers means of sustenance from several economic activities that are done there. Among these economic 
activities, stand out commercial fishery and tule extraction. From this last economic activity, it is generated a large quantity of handcrafts that for several years, families and inhabitants of San Sebastian del Sur have as their main source of income.

\subsection{Main goods and handcrafts made out of tule}

Among the handcrafts and goods handcrafted and made out of tule in the locality of San Sebastian del Sur, can be mentioned chairs, curtains, armchairs, easy chairs, different types of containers for different purposes, such as the tortillas' containers, tables, blowers, bedrolls and matting (petates), baskets, etc. Tule as a raw material is extracted from Zapotlán's Lake where it growths spontaneously and wildly. This natural resource is recollected by the inhabitants of the municipality of Gómez Farías, who do not depend or are required to hold a permission granted by municipal authorities to cut tule, to dry it and to sell it.

\section{Research methods}

A study was conducted to analyze the economic and social development of handcrafters who carry on productive activities using tule as a raw material in the making of handcrafts at the locality of San Sebastian del Sur, in the municipality of Gomez Farías, Jalisco. Data was obtained by means of a random survey based on the roster of handcrafters, which is a list of registered ones. This was done with the purpose of getting to know the different economic and social aspects of producers. The following data was obtained: Number of surveyed: 33; number of workshops visited: 33 . Trades of handcrafters and producers were classified in 4 groups, out of which it was found that the 33 persons surveyed were dedicated to the following activities: Manufacturing of rustic furniture: 9. Hand-woven of furniture and handcrafts: 7. Manufacturing of matting and bedrolls: 15. Cutters of tule: 2 .

\section{Analysis of results}

The percentages of families who are dependent of related activities with tule according to the survey results in the locality of San Sebastián del Sur, showed in Fig. 1 are the following:

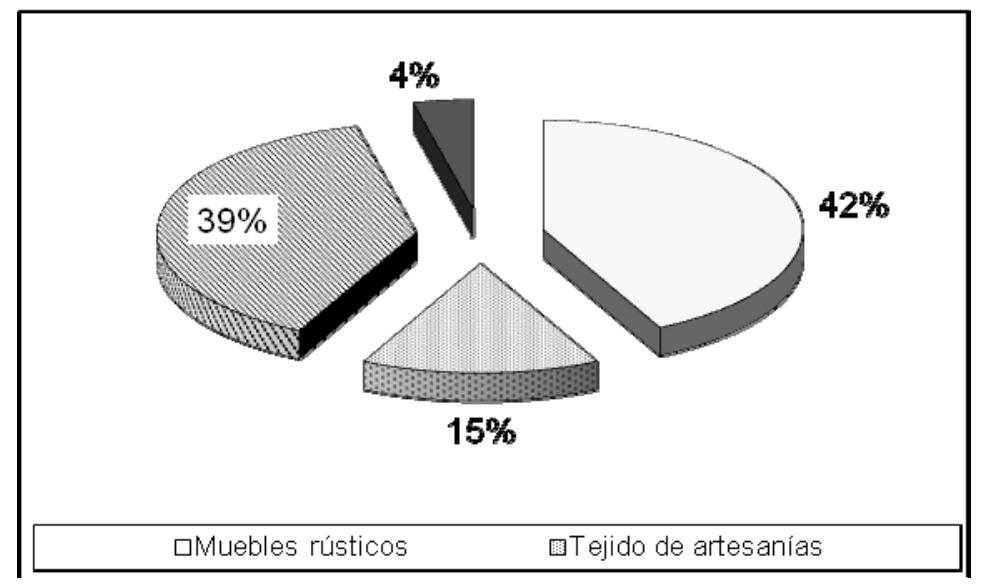

Fig. 1. Percentage of families depending of related activities with tule 
At the location of San Sebastián it was estimated the weekly average salary per worker in the different activities related to the processing of tule. This data was obtained according to the survey conducted by the craftsmen in the field, leading to the following results showed in Fig. 2:

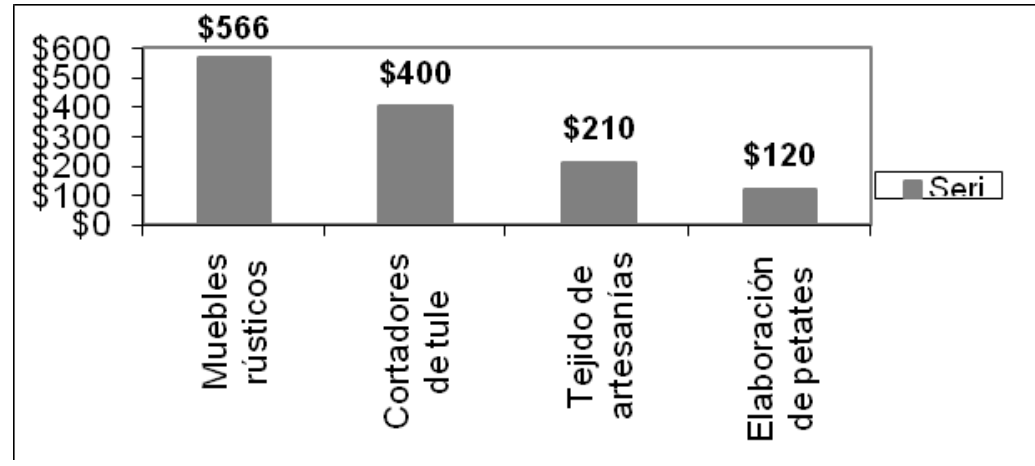

Fig. 2. Weekly average salary per worker.

According to the conducted study in the locality of San Sebastian, the percentage of craftsmen affiliated to associations and organizations was the following:
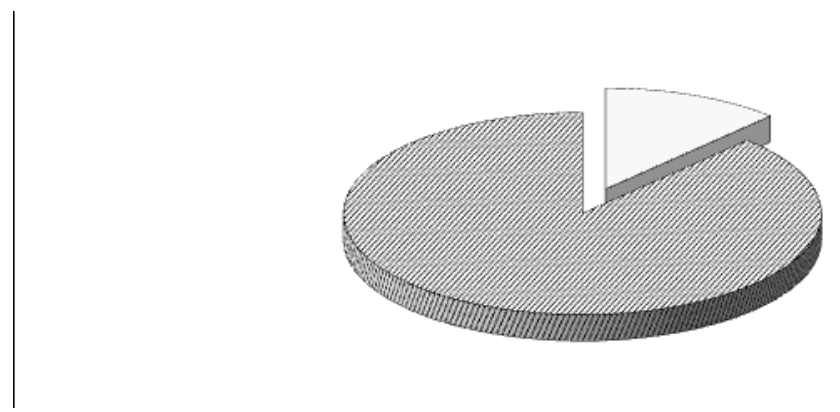

$\square \mathrm{Si}$ Ⓝo

Fig. 3. Percentage of craftsmen affiliated to any organization or association

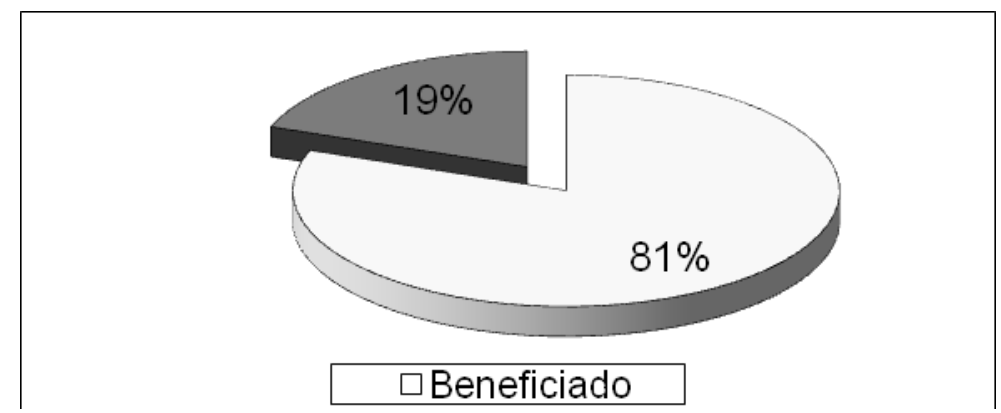

Fig. 4. Persons' opinion that have been benefited or affected the market for their products 
The majority of craftsmen (94\%) in the location of San Sebastian do not receive any type of support from any institution or dependence, while a small number of workers sustained not receiving economic support and promotion for their products and goods mainly from state and municipal institutions. $81 \%$ of the surveyed persons have the opinion that the market has been benefited in the last years due to there are more demand of their products and goods. Only $19 \%$ perceived that has been affected selling their products.

$45 \%$ of persons are sure that exists more pollution, $42 \%$ say to be in equal conditions tan before and only 13\% perceives less pollution in Zapotlan's Lake.

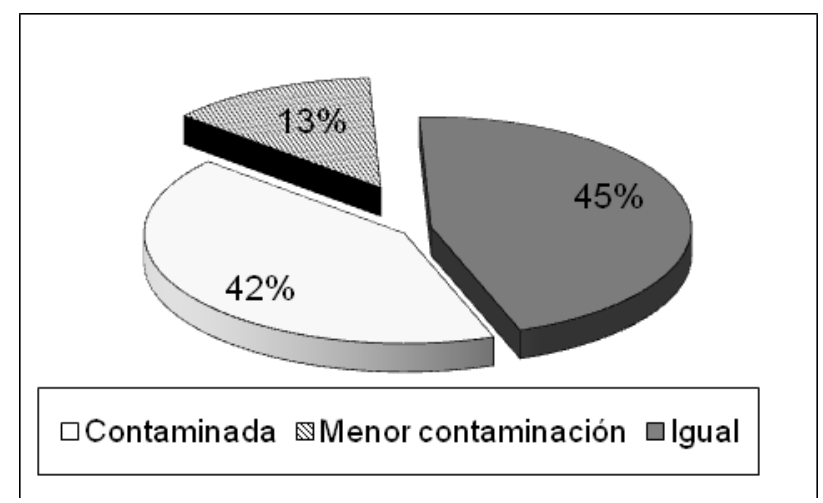

Fig. 5. Perceptions of surveyed persons on pollution at zapotlan's lake

\section{Discussion and comments on organizational sustainability based on the research results}

The presence of bundles of tule covering around one third of surface at Zapotlán's Lake (Universidad de Guadalajara, 1995), it is important for the nesting, refuge and protection of several species of fishes, tilapia, and carps and also for several species of birds. Tule's plant serves as the food for some species beginning from the organic material which becomes detached from the roots, regulates water's temperature thus the environmental temperature. In the following months after November, the plant is affected by groups of birds know as zanates who build their nest to sleep and to protect against the bundles of tule that the same birds break down. The biggest problem faced is that the proper bundles of tule palmilla (tule palm) used to weave chairs are flouting and invading the chubby tule used to manufacture matting and bedrolls and impede its normal growth and development. Thus, the bundles of tule need cleaning, or the tule palmilla damages the chubby tule. This problem has a solution. If there are extracted the bundles of tule palmilla that walk soils when the level of water goes up and cover the chubby tule.

The cutters claim that, among other problems, they do not count on the support and back up of any governmental dependence or institution through the granting of permissions to cut and exploit the tule. Also, the cutters claim that they do not receive any financial support in credits for the creation of facilities and infrastructure to carry on their activities and increase their productivity. One good example is the lacking acquisition of tools, cutters or motorboats to facilitate cutting of tule or conditioning of plots of land (patios or country 
yards) adjacent to Zapotlan's Lake. Similarly, there is lack of support to facilitate the drying of the cut tule. This situation always represents problems when tule is green. When tule is spread out and laid out in a country yard or patio for the processing of drying, it last from 3 to 4 days. There are some spells, mainly during the period of ebb tide in which tule is dried without being cuted, stating a little bit green. However, ecologically and environmentally these processes have some serious consequences which affect the local economics and environment.

Cultivation and exploitation of tule constitutes an important economic activity, mainly for the community of San Sebastian del Sur because it provides economic support to around three hundred families. About 80 families are economically benefited with the income received from the cutting, drying and transport of tule. Around 140 families are benefited from the handcrafted production of goods made of both varieties of tule, the palmilla tule and the chubby tule as the main raw material. Out of these 140 families, 120 are self-considered handcrafters of matting and bedrolls (petateros).

Around half of the 55 handcrafters registered in the Trade and Commercial Association have their own workshops, while the other half only work in assembling plant because they do not count on the instruments of a workshop properly equipped. Around 70 families receive income from intermediation, hoarding, stockpiling and commercialization activities of products derived from tule. The cutters of tule dry their raw material and make even up to two bunches per one day. The two bunches are sold at an average price of 75-80 pesos each one, making 150-160 pesos per day. Regularly, this sale represents the daily family income of around 13 USA Dollars. Tule palmilla used for the manufacturing of chairs is sold to intermediaries; most of them are owners of small stores who stockpile it. Tule chubby is sold to the craftsmen at a price a little bit less expensive to be used in the manufacturing of matting and bedrolls (petates).

Most part of manpower employed in the cutting of tule is permanent and their trade was inherited from antecedent generations. According to the conducted field research, and due to the ongoing changes taking place in Zapotlán's Lake, every year there are less cutters, thus, in the years before, the cutting of tule was an activity which generated more employment than nowadays. In the years before, the cutters formed a group and became a formal association of tule's cutters. Some of the actual cutters are temporarily workers in this activity, more specifically when they do not find a better remunerated employment.

The craftsmen produce different goods using as the main raw material tule, such as matting, bedrolls, hats, chiquihuites (containers in form of wide baskets), shadows, traditional chairs, high chairs, seamstresses, etc. From a roll to a bunch or bundle of tule handcraft up to seven matting which the craftsmen sell to a price of 30 pesos each one, an equivalent of two USA dollars and 40 cents, obtaining up to 210 pesos (almost 17 USA dollars) with an original investment averaging 80 pesos, the cost of one bunch of tule. A bunch of tule is formed with 5 or 6 big hands (manotadas) of tule. The cost of one big hand is approximately 20 pesos and it is the base to manufacture one chair which is sold at a price of 50 pesos to the intermediary o middleman. The cost of materials of one chair also includes besides the big hand, a wood branch of pine whose costs is up to 15 pesos, a cost that has been increasing when used to be 1.50 pesos several years ago. In one workshop where regularly work five craftsmen achieve to produce up to 70 chairs per week which are sold to the intermediaries and middlemen at a price of 70 pesos as an average. 
This price can improve depending on negotiations and trading with intermediaries and middlemen. Many cutters supply raw material to their own families who are in charge of the crafting of handcrafted products, widening with this situation the economic benefits and adding value. In other cases, there are conducted some practices of half by half ("medieros") between the cutters and the handcrafters. This is to say, after the selling of products; both cutter and handcrafter share the benefits in the same proportion, half and half.

Nowadays, the relationship among handcrafters of tule registered in one association at the location of San Sebastian del Sur is 55.16 years ago, the association was formed by 42 partners and set as the main aim the founding and building of the craftsman's house (Casa Del Artesano) as the market place in which their handcrafted production can be exhibited and sold. The three levels of government, Federal, State and Municipal contributed with donations of materials for the construction, while the partners made manpower contributions. However, most of the craftsmen members of the Association do not made any contributions of manpower and finally only six partners did it, and who nowadays exhibit and sell their handcrafted products in a separated way at the craftsman's house. This craftsman's house is located at one side of the Federal Highway Guadalajara- Cd. Guzman, in an adjacent location to the Municipal Cemetery. The person who was at the front and in charge of the Association, he has also the ownership of land and building. Originally the land was signaled by the Municipal Government of Gomez Farías for the construction of the craftsman's house. However, lately it was found that this land did not have any proprietorship according to the archives of the Public Register of Ownership.

Thus, nowadays, the ownership of the craftsman is the "apple of discord" and the cause of several conflicts due to the other craftsmen wants to participate of the benefits with the support of the municipal government. One of the former municipal officials who tried to benefit a group of craftsmen who do neither exhibit nor sell their products at the craftsman's house, had sent official letters to the Public Notary requesting a change in ownership regime and claiming that it is municipal's ownership. Despite of this, there is not one organization of craftsmen to whom it may classify among these who count on their own workshops, approximately half of the 55 registered members, and those who sell or "maquila" their own manpower for the former. Thus, those who sell their own manpower, do not have their own equipment, tools and facilities to establish their own workshop.

According to our own research, the interviewed assure that sales are declining. Today, they argue, sell less than 10 years ago. The middlemen and intermediaries are who more profits obtain from the commercialization of the handcrafted products. In order than a handcrafted product reaches the final consumer, it is required at least a three level's distribution channel, and this is to say that at least there are two intermediaries between producers and consumers. The intermediaries are the ones who attend national markets and to a lesser extent they export the handcrafted products to some parts of United States, Canada, Puerto Rico, England and Japan. The terrorist actions of September 11, 2001 had affected missing some orders of handcrafts. Some of the problems that the craftsmen face are those related to the lack of training programs to develop and preserve handcrafter techniques, financial support, and obtaining credits to extend basic production infrastructure, and of course, staffing and consultancy for direct exports of their products to the international markets. All these actions will benefit the economic income of more than 300 families in San Sebastián del Sur, Jalisco. 


\section{Conclusions}

The exploitation of tule represents an economic activity that provides income to approximately three hundred families living at the settlement of San Sebastian del Sur. Nevertheless, in the last few years the income has been decreasing due to the environmental changes and to the rehabilitation of Zapotlan's Lake to host the Pan-American Games in 2011. Both, the environmental changes and rehabilitation of the lake represent a serious threat to the economic efficiency and environmental sustainability. To achieve equilibrium between environmental sustainability and economic sustainability must be one of the main goals of the rehabilitation programs. Thus, the best indicators are required under a systematic study to determine the most adequate levels of environmental sustainability and economic efficiency. The limited social organizational capital and the lack of adequate forms of organization for the productivity, contribute to limit the scope and economic benefits that must provide an adequate exploitation of tule from Zapotlan's Lake. Disorganization of cutters and craftsmen of tule is the source of profound and increasing conflicts that not only block and limit the scope of better levels of productivity and family income, but also make difficult the pacific coexistence and living together and spoil the community's quality of life. Lacking a consultancy program to exports of handcrafted products has an impact on lower income to the families of cutters and craftsmen, because who actually obtain the greater part of profits are the intermediaries who take part on the commercialization processes and distribution channels.

Some characteristics of specificity and appropriateness of social and human capital involve economic, social and political relationships among individuals who are members of organizations, making complex their effects. Market is a social construction that makes operational social relations. Both capitals can be important resources of the competitive advantage, assuming that reside in the members or it is specific to the organizations as integral parts of resources that are unique and that are no observables. Organizations with higher levels of social and human capital generate more competitiveness than those with lower levels. A sustainable economy requires programs aimed to improve social and human capital.

\section{Recommendations}

Some recommendations after this research are formulated below:

- Design a program to promote handcrafted activities derived from the exploitation of tule that in a parallel form to the rehabilitation program of Zapotlán's Lake, establish the right indicators to achieve equilibrium between economic efficiency and environmental sustainability.

- To set a program of export consultancy with the support and technical staffing from students of international business at University of Guadalajara that provide the knowledge, skills and contacts in such a way that tule's craftsmen directly commercialize and market their own handcrafted products in the international markets.

- To propose a program for development of organizational and social capital and new forms of organization aimed to increase productivity and competitiveness of the craftsmen, thus increasing their family income and promoting employment creation and improve the quality of life of the whole community of San Sebastian del Sur. 


\section{References}

Baker, W. E. (2000). Achieving success trough social capital. San Francisco, CA: Jossey-Bass.

Burt, R. S. (1997). "The contingent value of social capital” Administrative science Quarterly, 42, 339-365

Joyce, Paul (1998). "Management and innovation in the public services". Strategy Change, 7. 54-63

Leana, R. Carrie; Van Buren III, Harry (1999). “Organizational social capital and employment practices" Academy of Management Review, Vol. 24, No. 3. Ohio.

Portes, Alejandro (1999). "Capital social: Sus orígenes y aplicaciones en la sociología moderna", Carpio, Jorge y Novaconvsky, Irene (comp.), De igual a igual. El desafío del Estado ante los nuevos problemas sociales, Fondo de Cultura económica-SiemproFlacso, Ciudad de México.

Universidad de Guadalajara (1995). Ordenamiento Ecológico de la Cuenca de la Laguna de Zapotlán el Grande Jalisco, Gobierno municipal, Cd. Guzmán, Jalisco. 
(C) 2012 The Author(s). Licensee IntechOpen. This is an open access article distributed under the terms of the Creative Commons Attribution 3.0 License, which permits unrestricted use, distribution, and reproduction in any medium, provided the original work is properly cited. 